\title{
Problemas e possibilidades de participação comunitária no controle das grandes endemias no Brasil
}

\author{
Community participation and control of endemic \\ diseases in Brazil: problems and possibilities
}

João Carlos Pinto Dias 1,2

1 Centro de Pesquisas René Rachou,

Fundação Oswaldo Cruz. C. P. 3173, Belo Horizonte, $M G$ 30190-002, Brasil.

2 Faculdade de Medicina, Universidade Federal de Minas Gerais. Av. Alfredo Balena 180 Belo Horizonte, $M G$ 30140-002, Brasil. jcpdias@netra.cpqrr.fiocruz.br

\begin{abstract}
Community participation (CP) is considered one of the most important elements for the control of endemic diseases in poor countries, particularly for prevention and epidemiological surveillance. Mainly affecting the poorest segments of the population, endemic diseases are costly and require specific government action aimed at efficient, egalitarian, universal health system, where CP acts in a guardian, monitoring capacity and entails other specific tasks. Despite its rationality, CP has not been encouraged in countries like Brazil, due to the highly centralized nature of political power and activity. Several examples and situations of CP in Brazilian endemic diseases are described and discussed in the article. CP for endemic disease control should be seen as an ongoing social process, a profound social exercise, and a great challenge for the country as a whole and the new Unified Health System now being implemented in Brazil.

Key words Consumer Participation; Community Participation; Communicable Disease Control; Health System; Public Health
\end{abstract}

Resumo A participação comunitária (PC) ativa, consciente e permanente é um dos elementos fundamentais no controle das grandes endemias em países como o Brasil, particularmente em termos de prevenção e nos seus estágios de consolidação e vigilância. Afetando especialmente as populações mais pobres, essas endemias são altamente lesivas e pressupõem ação específica do Estado, no que se refere a um sistema de saúde equânime, universal e competente, em que a PC é chave, não apenas como elemento de controle social, mas também como executora e mediadora de ações finalísticas. A despeito de toda sua racionalidade, a PC não tem sido exercitada ou estimulada no País de forma sustentada e conseqüente pelos governos e lideranças, como reflexo da própria centralização política e de poder ainda vigentes. Exemplos de situações e possibilidades são ilustrados no artigo com relação a importantes endemias brasileiras. Entendida como processo social profundo e de permanente construção, a PC no controle de endemias se impõe como exercício de cidadania e um grande teste para o Sistema Único de Saúde e para o País.

Palavras-chave Participação Comunitária; Controle de Doenças Transmissíveis; Sistema de Saúde; Saúde Pública 


\section{Introdução}

Do ponto de vista epidemiológico, as chamadas grandes endemias têm assolado populações ao longo da história, com grandes perdas sociais, localizadas principalmente no nível dos extratos menos favorecidos. As doenças tropicais, verdadeiros desafios à conquista $\mathrm{e}$ colonização dos trópicos, não apenas confirmaram a regra e se dispersaram sobre milhões de pessoas, como também têm sido capazes de resistir à modernidade: no século atual, mercê de grandes avanços científicos, essas doenças concentraram-se via de regra nos países subdesenvolvidos, como uma indicação suplementar de que a evolução da ciência e da tecnologia também pode participar do processo de exclusão de pessoas e populações (Nakajima, 1989). Quanto ao significado social, mais da metade da população do planeta encontrava-se sob a ameaça das doenças tropicais em 1993 e quinhentos milhões de indivíduos estavam infectados por pelo menos uma delas (Remme et al., 1993). Na base de seu conceito, ultrapassada a fase de teorias simplistas e de causalidade meramente biológica, cada vez mais se impôs a necessidade de que fatores sociais e políticos fossem contemplados como elementos fundamentais, tanto em sua compreensão, como em seu controle (Briceño-León \& Dias, 1993). Desde o final dos anos 50, após reiterados insucessos dos sistemas de saúde no Terceiro Mundo, as discussões caminharam para a busca de profundas reformulações que alcançaram o ápice em Alma-Ata. Particularmente nos países mais pobres, onde têm persistido as doenças endêmicas e as epidemias, uma série de tentativas mostrou-se insuficiente na montagem de sistemas eficientes de saúde. A visão e as estratégias seguiam burocráticas, biologicistas, hospitalo e medicocêntricas. Há quase três lustros, Pitt (1983:1) proclamava à Organização Mundial de Saúde (OMS): “Tropical diseases are indeed diseases of the poverty, since they are prevalent in socially and economically depressed areas. Unless these social and economic roots are not also corrected, success in disease control does not appear to be attainable”. À época, emergindo dos postulados que Alma-Ata lançara aos povos por uma vontade real na busca de saúde para todos, preparavase no Brasil a VIII Conferência Nacional de Saúde. Ali seriam reiterados os princípios da cidadania e textualmente se afirmava que "em primeiro lugar, fique claro que as mudanças necessárias no sistema de saúde transcendem os limites de uma reforma administrativa ou financeira" (MS, 1986:2).
A história fazia os caminhos. No contexto internacional, o Brasil mostrara-se competente no controle da malária não amazônica e o programa de doença de Chagas lograva avançar, depois de priorizado em 1982, cobrindo toda a imensa área endêmica e reduzindo drasticamente a transmissão vetorial da parasitose. Ainda assim, preocupavam os aspectos de sua consolidação (fase de vigilância) praticamente impossível de levar-se a termo com um programa vertical.

Não obstante, as leishmanioses se urbanizavam e se expandiam, enquanto que, para o desafio da esquistossomose, o governo continuava gastando rios de dinheiro em moluscicidas caríssimos, devastadores do ambiente e ineficazes contra os caramujos. Muito mais tarde, cólera e dengue viriam a incorporar-se neste contexto, com características muito próprias e enorme velocidade de dispersão, trazendo à baila o julgamento direto de dois subdiretórios que as autoridades ministeriais, em geral, relegavam a plano inferior: saneamento básico e atenção primária à saúde. Uma terceira e terrível emergência, a Aids, foi mais fundo, a demandar concretamente ações educativas e mudanças comportamentais que fossem eficientes e duradouras, um outro espaço considerado ainda mais obscuro e 'sem importância' no contexto dos inseticidas e das operações de guerra vigentes. Na ótica de então, partia-se do princípio que as grandes endemias eram totalmente vulneráveis às clássicas ações de controle de vetores, em paralelo com a cultura vigente de que a estratégia e o modelo somente teriam eficiência numa perspectiva vertical e centralizada, que a população era necessariamente ignorante e não cooperativa, e que, com raríssimas exceções, nenhum sistema local teria competência para ser incorporado às 'campanhas' (Dias \& Dias, 1985). Também era usual, nesse contexto, pensarem-se as endemias exclusivamente em termos de sua 'fase de ataque', justamente aquela mais militarizada e mais vertical, portanto a mais sintonizada com a lógica do poder vigente. Em paralelo, o regime da época proibia formalmente toda tentativa de organização acadêmica ou popular, o que literalmente obstruía no nascedouro qualquer hipótese de participação comunitária (PC). Esse foi, sumariamente, um quadro recente e os impasses que a comunidade científica e a Saúde Pública viveram em praticamente toda a América Latina tiveram repercussões tangíveis no presente, que Breilh \& Granda (1989:1.122) descreviam: “ Los Estados Latino-americanos, capitalistas y dependientes, han sido definidos como 'eslabones débiles' del capitalismo mun- 
dial, en vista de la fragil estructura económicosocial sobre la que se asientan genera una acumulación de contradiciones y de dificultades para resolvelas, dando lugar a una superestructura sobrecargada de tareas". As bases da reforma sanitária no Brasil começaram a cristalizarse em 85-86, com a queda da ditadura e a realização da VIII Conferência. Par e passo com a transição política, caminhavam os processos de transição demográfica e epidemiológica, bem como a revolução tecnológica, já apontando para um futuro próximo de globalização da sociedade e agravamento das distâncias sociais (Amâncio Filho, 1994; Rivas, 1985). Ao fim dos anos 80, no plano da política mundial e sob a denominação enganosa de ajuste, iniciou-se uma avassaladora transformação das estruturas econômicas e um desmantelamento do Estado. Na busca de um equilíbrio fiscal (entendido como instrumento básico ao controle da inflação), iniciou-se um processo de aumento de tributos, reduzindo-se os subsídios à produção nacional, limitando-se os programas sociais e privatizou-se o capital social: em nome da abertura econômica e do aumento da produtividade, passou-se ao mercado o papel regulador que sempre coubera ao Estado (Rodriguez et al., 1992).

A evolução mais recente dos conceitos e perspectivas embutidos na reforma sanitária aponta cada vez mais fortemente para a necessidade da ampla participação social no projeto maior da saúde, em termos da necessária descentralização, da construção democrática das alternativas, do encontro da eficiência e do controle social. A questão da participação comunitária tem sido considerada como uma chave e um estrangulamento em face das perspectivas da saúde, em países como o Brasil, onde "as ações de saúde sempre se distribuíram de maneira estanque, desordenada e descontínua dos pontos de vista operativo, político ou institucional (...) com o poder de decisão das áreas da saúde geralmente desvinculado de instituições tecnicamente normativas, como a Universidade, e muito distanciado da própria clientela" (Dias \& Dias, 1985:127-128). No mesmo contexto, as grandes endemias constituem hoje um dos maiores desafios à competência do modelo pensado, desde que afetam e dizimam exatamente as populações que dependem diretamente do funcionamento desse modelo. Sua abolição no primeiro mundo atesta que são preveníveis, em geral, na dependência de ascensão social e de acesso às tecnologias já disponíveis. Como enfocá-las num Sistema Único de Saúde (SUS), cujas bases éticas e políticas pressupõem a eqüidade e a universali- dade? As presentes notas têm por objetivo central uma reflexão sobre a formulação e as perspectivas de uma participação efetiva das populações no controle das endemias, tomando por base o exemplo brasileiro em épocas recentes.

\section{Aspectos gerais das grandes endemias no Brasil e suas relações visíveis com a PC}

O panorama atual das grandes endemias brasileiras apresenta três aspectos básicos, sob o aspecto epidemiológico-operacional e com vistas à PC:

a) Urbanização de clássicas endemias que tradicionalmente eram de natureza eminentemente rural, como a esquistossomose, a doença de Chagas, as leishmanioses e a própria malária, por conta do processo demográfico-social decorrente do novo modelo urbano-industrial que desde os anos 50 se implantou no País. Essa conotação da malária não corresponde a uma mudança radical nos padrões clássicos da endemia, mas a uma situação epidemiológica relativamente nova e adicional no contexto brasileiro. O surgimento de importantes focos de transmissão palúdica em Manaus, Porto Velho e outros espaços urbanos da Amazônia vem se dando em paralelo com outras expressões epidemiológicas tradicionais da doença, como a malária das fronteiras agrícolas, das frentes de desmatamento, dos garimpos, das reservas indígenas etc.

Mudanças importantes ocorreram no contexto das relações de produção, cada vez mais dificultando a fixação do homem no campo, especialmente o pequeno produtor, estimulando a figura dos 'bóias-frias', aos poucos gerando associativismo e organização de categorias etc. (Barata, 1993; Briceño-León \& Dias, 1993; Dias \& Dias, 1985);

b) Evolução epidemiológica dos agravos e dos respectivos programas de controle, no que diz respeito à demanda de vigilância epidemiológica e de importantes câmbios estratégicos em sua formulação. Neste sentido, contemplam-se, de um lado, a superação da clássica 'fase de ataque' do programa antipalúdico em toda a área não amazônica e do controle da doença de Chagas em praticamente toda a área endêmica e, de outro, mudanças fundamentais na estratégia de controle da esquistossomose (praticamente desativando o uso massivo de moluscicidas) e da própria malária (privilegiando o pronto diagnóstico e tratamento dos casos sobre o clássico uso prioritário dos inseticidas). Por outro lado, aumentada a expectativa de vida das populações em geral, novo pa- 
norama surge com a superposição de doenças crônico-degenerativas (diabetes, hipertensão, neoplasias) e da própria idade ao espectro tradicional da doença de Chagas, da esquistossomose e da malária, como novo desafio ao manejo destas endemias (Dias, 1993).

c) Surgimento (ou recrudescência) de antigas doenças, como dengue e cólera, em panorama epidemiológico novo e específico, ao lado da expansão do HIV, que se instalou inexoravelmente e hoje se superpõe e modifica a história natural de outras doenças, como a tuberculose, a doença de Chagas, várias micoses e a toxoplasmose.

No campo específico e descritivo, as chamadas grandes endemias brasileiras seguem presentes e importantes no País, representando valiosas perdas humanas e financeiras, especialmente nos segmentos sociais menos favorecidos, que são por elas os mais afetados (Schmunis, 1997; Banco Mundial, 1993). Por outro lado, sua ocorrência reduz a auto-estima da população e - claramente - a credibilidade do SUS (Briceño-León \& Dias, 1993). De modo geral, o enfoque de todas elas não apenas admite, mas, hoje, requer a participação comunitária em todas as etapas de seu controle. Essa necessidade ocorre à luz tanto da doutrina do SUS, como do resultado das modernas análises epidemiológicas, que trabalham em conjunto os fatores de risco e as conotações específicas de cada agravo na sua distribuição histórica e espacial. Resumindo por algumas doenças e aproveitando algumas de suas peculiaridades específicas, de maneira simplificada poderiam exemplificar-se quanto à PC no controle de endemias:

\section{Malária}

Em nível mundial, representa a mais séria e impactante das doenças transmissíveis, colocando sob risco $40 \%$ da população dos trópicos, incidindo em provavelmente mais de trezentos milhões de indivíduos/ano, penalizando drasticamente o continente africano (mais de $90 \%$ dos casos e mais de 1,5 milhão de mortes anuais) e afetando mais de um milhão de pessoas/ano nas Américas (OPS, 1997; Tauil, 1997; WHO, 1993). Para o Brasil, com mais de 450 mil casos anuais em 1996, deve-se considerar distintamente as áreas amazônica (mais de $99 \%$ dos casos) e não amazônica. Na primeira, os programas tendem a ser bem mais centralizados e verticalizados, mais centrados em ações de ataque e a exigir escalonamento de prioridades e diferenciação nas estratégias conforme o perfil epidemiológico. Por exem- plo, o conhecimento das estratificações de risco pode otimizar os recursos em áreas estratégicas, conforme os elementos de controle mais pertinentes à situação (Marques \& Cárdenas, 1994). Na área não amazônica, a perspectiva imediata e a longo prazo concentra-se essencialmente em vigilância epidemiológica, situação em que a PC é cada vez mais requerida por razões éticas, técnicas e mesmo econômicas. No Brasil, em 1996, de 455.194 exames positivos, $77,9 \%$ foram produzidos em áreas de alto risco, $15,8 \%$ nas de moderado e $6,3 \%$ nas de baixo risco de transmissão, restando apenas 161 casos autóctones (0,03\% do total), na área não amazônica (OPS, 1997). Há distâncias e dispersão enormes, num contexto em que as pressões de transmissão também podem ser máximas, demandando grande agilidade e eficiência para que se poupem vidas humanas e se contenha o ímpeto da expansão da endemia. Importante notar que historicamente a malária brasileira era predominantemente não amazônica, macrorregião em que o esquema clássico e vertical dos anos 50 funcionou a contento e até motivou a esperança da erradicação da doença no Brasil. Foi a era 'soperiana', nome originado do grande teórico do combate à malária nas Américas, Fred Soper, época em que a malária amazônica significava pouco em termos de proporção de casos, e quando o padrão epidemiológico do restante do País era relativamente homogêneo, salvo exceções como a malária das bromélias, no litoral Sul. A idéia da erradicação cristalizou-se nos anos 50, a partir da IV Conferência Pan-Americana e VIII Assembléia Mundial de Saúde, entendendo como erradicação "o fim da transmissão dos casos infectantes", utilizando o modelo de campanhas curtas e perfeitas, numa estratégia comum a todos os países e reduzida à sua máxima simplicidade, pela supressão de toda e qualquer particularidade (Barata, 1993).

Hoje, a complexidade ecológica e social do paludismo amazônico desafia técnicos e governos. Pequena e dispersa população, falta de saneamento, de paredes a borrifar, de pessoal capacitado e disponível, de continuidade operacional, de transporte ágil e, muitas vezes, de insumos básicos, dificultam o tradicional programa, lado a lado com a escassez de pessoal técnico e a dispersão político-administrativa. $\mathrm{Nu}$ ma outra escala, as prioridades de controle têm que seguir os critérios epidemiológicos e sociais, o que é grande problema quando - pela extensão da endemia e dos recursos envolvidos - interesses particulares pesadíssimos podem vir a prevalecer através de lobbies e pressões. Escalonando as atividades e racionalizando re- 
cursos, a incidência da malária tem se reduzido lenta e gradualmente nos últimos anos no Brasil, mercê também de mobilização humana, como, por exemplo, a desativação recente de garimpos em Mato Grosso. Além da redução global da incidência, hoje no Brasil se nota melhora do quadro epidemiológico, pela redução da proporção majoritária da malária falciparum, de 54,2\% em 1986, para 28,5\% em 1996 (OPS, 1997; Marques \& Cárdenas, 1994).

No modelo tradicional, o combate à malária priorizou a luta contra o vetor - principalmente a química contra o inseto adulto -, subsidiada por eventuais obras de saneamento, por controle larvário e por tratamento dos doentes. A partir de 1992, após a Conferência Mundial de Malária (Amsterdã), evoluiu-se para objetivos gerais de um controle integrado, em busca da prevenção da mortalidade e da redução da morbidade e das perdas sociais decorrentes. É de destacar-se que o processo de organização dessa Conferência foi eminentemente participativo, tendo como base estudos por país e a realização de pré-conferências macrorregionais. Em particular, o tom mais avançado e impulsionador das principais mudanças veio da conferência americana, realizada no Brasil, onde pesquisadores e prestadores de serviço debateram exaustivamente o tema, valendo-se das práticas locais e das novas realidades epidemiológicas e institucionais (nota do autor, participante das conferências americana e mundial).

As estratégias básicas centraram-se no homem infectado, no diagnóstico e ação precoce, em vista do caso e da expansão da endemia, e na otimização de uma epidemiologia capaz de caracterizar o evento e direcionar efetivamente as ações de controle. Como requisitos fundamentais, ficaram claramente estabelecidas a necessidade de vontade política, a integração da luta antimalárica no sistema de saúde, a efetiva PC e a disponibilidade real de recursos humanos e financeiros (Tauil, 1997). A PC pode e deve envolver-se em todas as etapas e níveis do programa antipalúdico, nesta nova formatação, especialmente quando o controle da malária é previsto para ocorrer de modo permanente, integral e auto-sustentável. A começar pela definição de prioridades e alocação de recursos (âmbito técnico-político), os três níveis de governo e a população interessada têm que participar de forma ordenada e harmônica, inclusive envolvendo outros e importantes espaços sociais como ONGs, sindicatos, Igreja etc. Detectar e tratar prontamente os casos é a ação básica e prioritária, preferencialmente de nível local, norteadora do esquema epidemiológico que irá definir as ações complementares, como o controle vetorial e outras possíveis intervenções ambientais. A organização local e o bom funcionamento do sistema de saúde e outros correlatos são peças fundamentais neste contexto, aí claramente envolvidos o nível de consciência da comunidade, sua capacidade de organização e seu poder político. Aqui já aparecem claramente algumas posições de BriceñoLeón (1994) e Dias \& Dias (1986), quanto ao enfoque participativo promovendo a responsabilidade individual para a cooperação coletiva, à desconfiança das populações no Estado, à superação do estilo autoritário do pessoal de saúde e a três aspectos essenciais na motivação e percepção da população no que tange o controle de doenças: a vida muito calcada no aqui e no agora, a sua maneira integrada de ver as coisas no contexto geral de suas vidas e a sua disposição em mobilizar-se quando são claros e concretos os motivos e problemas. Na sua essência, a prevenção individual, o diagnóstico e o correto tratamento dos casos de malária pressupõem conhecimento, mobilização das pessoas e acesso aos serviços habilitados. Por exemplo, é cada vez maior a demanda passiva de exames de laboratório no diagnóstico da malária nas Américas e no Brasil, o que indica o caminhar da descentralização, da maior sustentação das ações, do grau de consciência das pessoas etc. (Marques \& Cárdenas, 1994; OPS, 1997). O grande problema da malária americana encontra-se nos ambientes ecológica, geográfica e socialmente complexos das florestas úmidas. Nesse contexto, não se podem desconhecer os imensos complicadores da malária amazônica, em termos, principalmente, da grande dispersão e da mobilidade das pessoas, significando talvez o maior desafio à inteligência e à criatividade dos administradores e trabalhadores da saúde. Dois exemplos recentes ilustram, no Brasil, o valor e a exeqüibilidade da PC em programas de malária, com conotações distintas: 1) Em 1987, Silva (1988) descreveu a implantação de um programa integral de saúde em comunidades do Maranhão, com ampla PC desde o seu diagnóstico: a malária era hiperendêmica, e o programa oficial, cheio de problemas operacionais, era insuficiente. Os casos, em maioria imigrados da Amazônia, tardavam em média 34 dias para serem tratados, com isso proporcionando casos autóctones de malária em grande quantidade. A demora devia-se a fatores diversos, todos de natureza organizacional e administrativa. Organizado e assumido pela população, com total parceria da Superintendência de Campanhas de Saúde Pública (Sucam) regional, os casos suspeitos passa- 
ram a ser imediata e adequadamente diagnosticados e tratados, extinguindo-se assim a malária autóctone e desdobrando-se o projeto em muitas outras iniciativas de organização comunitária, inclusive de saúde, com evidente aumento da auto-estima da população e descoberta de parcerias e sustentabilidade das ações. 2) Em 1992, em face do preocupante quadro da malária amazônica, o então Ministro da Saúde, Adib Jatene, buscou com a Fundação Nacional de Saúde (FNS) as necessárias parcerias estaduais para viabilizar a necessária descentralização do programa federal, seguindo os ditames da racionalidade e do novo momento político. A distribuição de recursos envolvia aspectos partidários e interesses políticos, ao lado de uma tradicional cultura de os Estados deixarem à União o encargo das ações contra a malária, fatos enormemente dificultadores ao câmbio pretendido. Como uma série de reuniões técnicas entre o Ministério e as Secretarias Estaduais de Saúde não lograva fazer avançar o projeto, o Ministro convocou os governadores de todos os estados para um seminário político e científico durante dois dias, no Pará, quando a malária foi por eles estudada, e a melhor compreensão dos fatos ensejou uma nova postura política, com repercussão imediata e positiva no nível dos encaminhamentos necessários.

As perspectivas e necessidade de PC no controle da malária são muito grandes, sabendo-se também que no contexto amazônico requerem-se ainda algumas ações verticais e centralizadas. Trata-se de uma situação concreta e esperada, em que o objetivo básico é o controle da malária, a proteção efetiva da população. Reside o desafio exatamente em compatibilizar e otimizar o programa numa perspectiva responsável da necessária transição, exatamente um ponto em que a PC pode imensamente contribuir. Ao manter seus valorosos contingentes na Amazônia, a FNS deve amplificar esta transição, aperfeiçoando com os estados e municípios as parcerias e os desenhos programáticos que melhor atendam às peculiaridades locais e regionais do problema. Em particular, e como dado positivo, ressalte-se a enorme rede implantada de colaboradores voluntários na luta antipalúdica, operando há anos e silenciosamente nos Postos de Notificação da Malária (PNM), e cujo caso está a merecer estudo aprofundado. Já numa conotação mais geral de PC, uma questão básica desafia os parlamentares, administradores e programas de governo: a perspectiva que se coloca de inclusão do programa antimalárico como componente fundamental dos projetos de desenvolvimento da Amazônia Legal. Mais pontual- mente, aproveitando as indicações de conceituados especialistas, as perspectivas de êxito num programa integrado contra a malária amazônica dependem muito da construção de uma PC efetiva e permanente, como se pode depreender de cada tipo de ação proposta: a) apoio aos serviços locais de saúde para que adquiram a capacidade de diagnosticar e tratar rápida e eficientemente os doentes; b) fortalecimento de uma rede local/regional de laboratórios suficiente para o diagnóstico da malária; c) desenvolver e apoiar atividades de capacitação dos trabalhadores de Saúde Pública nas atividades de prevenção e controle; d) adequação e aperfeiçoamento de um sistema integrado de informação que agilize a vigilância epidemiológica; e) ampla disseminação de informações técnico-científicas apropriadas e dirigidas aos trabalhadores de saúde e à população, objetivando intensificar o diagnóstico e tratamento da doença e a prática contínua de hábitos e medidas de proteção individual; f) apoiar pessoas, grupos e instituições para que se ampliem as necessárias pesquisas operacionais que contribuam para o melhor conhecimento das situações locais da endemia e seu controle efetivo e permanente (Marques \& Cárdenas, 1994). Além destas, mais três situações se colocam no cenário da PC em malária, especialmente na perspectiva do SUS: 1) o controle social dos recursos, procedimentos e burocracia envolvidos no programa, a ser otimizado nos conselhos, comissões e conferências de saúde; 2) o aprimoramento da cidadania em geral para coibir e moderar o jogo de interesses e lucros que uma verdadeira indústria paralela da malária implantou em muitas partes das regiões endêmicas, e 3) o enorme potencial que a malária, por suas características de doença aguda e temporariamente limitante, tem de induzir e propiciar a solidariedade humana nos níveis grupal e comunitário, seja pelos cuidados pessoais, seja pelas possibilidades de autoajuda, substituição de pessoas em frentes de trabalho etc.

Como reflexão final deste tópico, lembre-se que a malária em nosso meio tem sido historicamente tratada e discutida quase que exclusivamente por elementos de governo, e de uma forma estanque e isolada no próprio problema que constitui. Como desafios essenciais à implantação de um programa integral, integrado e eminentemente participativo, dois dos reptos enunciados por Briceño-León (1994:173-174) devem ser enfrentados e equacionados:

"Como conectar o problema específico da doença com as metas globais de saúde e de bem estar social e econômico da população?" 
"Como outorgar a ajuda e a participação do Estado sem criar dependência?"

\section{Esquistossomose mansoni}

Entendidas as características da relação esquistossoma-homem, pode-se perceber por que a esquistossomose é uma das doenças mais difundidas no planeta, intrinsecamente ligada às maneiras de o homem morar, viver e trabalhar. Distribui-se em mais de setenta países e acomete duzentos milhões de indivíduos no mundo, com mortalidade estimada próxima dos duzentos mil casos anuais (Pereira \& Távora, 1994; Prata, 1997; Remme et al., 1993). No Brasil, ocorre a esquistossomose mansoni (SM), dispersa especialmente no Nordeste e Sudeste, trazida da África já nos primórdios da colonização européia, em virtude do tráfico de escravos; embora de difícil cálculo, o número de esquistossomóticos foi estimado entre dez e doze milhões de pessoas no Brasil (Amaral \& Porto, 1994; Ximenes et al., 1994). A dispersão da esquistossomose deu-se lenta e progressivamente no País, a princípio ligada ao tráfico de escravos, principalmente rural, instalandose por conta do baixo saneamento básico, da ampliação da fronteira agrícola (principalmente da cana, no Nordeste, e do arroz e hortaliças, no Sudeste) e da ocorrência do molusco transmissor. Paisagisticamente, a SM é doença de terras boas e bem servidas de água, em regime perene, principalmente em baixadas e coleções hídricas pequenas, onde a lavoura é mais fácil e agregados e familiares vão instalar-se, num contexto de distorções econômicas e injunções sociais (Pereira \& Távora, 1994). A contaminação das águas procede das fezes das pessoas infestadas, naturalmente num contexto de saneamento precário ou inexistente; em paralelo, susceptíveis se contaminam nas águas naturais infestadas por cercárias, mercê de vários tipos de contatos (trabalho, lazer, banhos, passagem). O ciclo da doença é relativamente simples (homem-água-caramujo-águahomem), mas de enorme complexidade social e profundamente adstrito à realidade e às necessidades cotidianas das pessoas. No passado, o controle da SM foi tremendamente problemático, com uma terapêutica muito difícil (drogas pouco eficazes e de grande toxicidade), saneamento pobre e disperso, mobilização comunitária e educação sanitária mínimas. Basta assinalar que, em 1994, nos estados endêmicos para SM, a cobertura de água encanada ainda era de $69,7 \%$ (49,2\% no Nordeste), e a de esgotamento sanitário, de apenas $35,4 \%$ (7,8\% no Nordeste), enquanto a taxa de analfabetismo alcançava 23,9\% no Sudeste e 55,8\% no Nordeste (Amaral \& Porto, 1994). O combate químico aos caramujos era a prioridade, mediante o uso de pesticidas caros, pouco eficientes e altamente lesivos ao meio ambiente. Neste quadro, vigente no País até os anos 80, a esquistossomose era considerada uma doença maldita, particularmente em face das formas hepatoesplênicas que incidiam em pelo menos $2 \%$ dos casos (Pereira \& Távora, 1994). Com o surgimento de drogas efetivas, de baixa toxicidade e de fácil administração, a partir dos anos 80 construiu-se uma nova e mais eficaz estratégia de controle da SM; o grande avanço na terapêutica, quando bem conduzida, mostrou-se muito eficaz na prevenção e na redução das formas graves, e também, quando executada em grande escala, na diminuição da prevalência local da SM e no virtual desaparecimento de formas agudas (Prata, 1997). Isso fez centrar o programa no diagnóstico e tratamento dos infectados, em larga escala e em toda a área endêmica, diretamente coadjuvada por medidas de educação e saneamento, ficando o uso de moluscicidas restrito a raríssimos casos focais de coleções hídricas com alta população de moluscos e elevados índices de transmissão da SM. Intensificado em nível nacional principalmente nos anos 90, o Programa de Controle de Endemias do Ministério da Saúde (PCE) expandiu-se pelo Brasil. Para se ter uma idéia, em Minas Gerais, onde cerca de 450 municípios são endêmicos para SM, o PCE, que cobria 13 deles em 1990, evoluiu para duzentos em 1995 e alcançou quatrocentos em 1997 (dados da Coordenação da FNS/ MG). Importante ressaltar o processo altamente participativo que envolve a instalação do PCE no município, partindo de um diagnóstico técnico prévio da situação epidemiológica (humana e malacológica). Seguem-se negociações para alocação de recursos (laboratório, insumos diagnósticos, capacitação, supervisão e medicamento pelo lado federal, com pessoal, mobilidade e instalação física pelo município. Aproveitam-se conferências e reuniões municipais de saúde para discussão do problema e programação conjunta, envolvem-se o sistema local de saúde, a rede de ensino, as associações comunitárias etc.

Do espectro negativo inicial, que incluía morte, sofrimento, perda de capacidade laboral e sensação geral de impotência, graças ao progresso científico e a bons trabalhos de campo (no Brasil), passou-se a uma situação de resolutividade e de perspectivas de controle da doença nos níveis individual e coletivo (Prata, 1997). No primeiro, a cura da parasitose e mesmo a regressão parcial de suas seqüelas depen- 
de de um diagnóstico relativamente simples e do acesso ao tratamento adequado; no nível coletivo, toda uma formatação, minimamente estabelecida na comunidade, impõe-se e depende de competência e desejo político. Em ambos os casos, e até pela epidemiologia própria da SM no Brasil, o bom funcionamento do SUS e ampla participação comunitária são elementos essenciais. Pode-se simplificar, entendendo que um programa de SM no Brasil pode começar massiva e centralizadamente, em níveis regionais ou municipais, mas em pouco tempo se fazem necessárias atividades descentralizadas para a consolidação do programa em clusters de localidades, bairros ou casarios onde remanescem focos residuais No espírito do presente volume e exemplificando como feito acima com a malária, as perspectivas e necessidades da PC no caso da esquistossomose poderiam pontuar-se:

- No caso da prevenção da SM, vários elementos cognitivos e comportamentais entram em jogo, cabendo ampla discussão e informação nos níveis comunitário e familiar. Mais dependente do comportamento do homem do que do vetor e diferentemente da malária, a transmissão da SM se faz fora de casa, e em circunstâncias muito variadas de contato do suscetível com águas naturais. O comportamento humano também sobressai no que toca à contaminação das águas com as fezes de portadores do verme. Neste contexto, toda uma série de hábitos e posicionamentos das populações interessa ao problema, desde a questão individual da higiene pessoal, até os aspectos mais gerais do acesso equânime à informação e ao saneamento básico. Este é um campo extremamente fértil na ação educativa que um programa de controle da SM poderia proporcionar, pois lida diretamente com a realidade imediata e vivida das pessoas. É nesta perspectiva que Freire (1976) idealizava sua ação cultural para a liberdade, pressupondo que toda prática educativa implica uma concepção do ser humano e do mundo. Caminho semelhante tomou Hollanda (1976), propondo a educação para a saúde como um processo de compreensão de vida, utilizando exatamente a SM como modelo de re-admiração e re-interpretação da realidade das pessoas e busca de câmbios para essa realidade. No 'modelo' SM, os níveis de discussão e de consciência da comunidade passam obrigatoriamente pela análise das relações de produção e das relações homem-água, homem-meio e homem-saneamento, não havendo como desencadear-se qualquer ação sustentada e coletiva se não forem claramente contempladas essas relações e se não for instituído um projeto ativo, comunitário, político e eminentemente participativo A historicidade e o caráter político e vivencial do ser humano definem essa situação: "Seres históricos e inseridos no tempo, e não imersos nele, os seres humanos se movem no mundo, capazes de optar, de decidir, de valorar. Têm o sentido de projeto (...). A relação entre a consciência do projeto proposto e o processo no qual se busca sua concretização é a baseada ação planificada dos seres humanos, que implica em métodos, objetivos e ações de valor (Freire, 1976:43).

- Na etapa de instalação e desenvolvimento do diagnóstico e tratamento dos infectados, a PC é requerida e extremamente oportuna. Intrinsecamente ligado ao PCE está toda a questão da logística do trabalho, da otimização das tarefas e etapas, da fundamental necessidade de grande cobertura e de mínima continuidade, da imprescindível colaboração de todos para que exames e tratamentos sejam realizados adequadamente etc. Normalmente, no PCE/ Brasil os insumos básicos de diagnóstico e tratamento são providos pela FNS (Governo Federal) aos estados e municípios, cabendo a estes a execução do trabalho, em máxima interação com as comunidades. Nesse ponto, o PCE já propicia ao SUS um aperfeiçoamento importante, reforçando o entrosamento entre as três esferas de governo e, mais ainda, é quando a comunidade começa a discutir e a trabalhar um programa específico (SM), que diz respeito a sua vida, que é um direito seu na medida em que foi negociado e implantado dentro da doutrina de eqüidade e universalidade do SUS (inclusive com recursos próprios) e que proporciona e requer a sua participação fiscalizadora. Ampliando seus limites técnicos, o PCE pode ainda propiciar o diagnóstico e o tratamento de outras enteroparasitoses de grandes grupos populacionais, na dependência de pequenos ajustes no exame de fezes e na disponibilização de medicamentos antiparasitários de amplo espectro e dose única, como o albendazol e o secnidazol (Pimenta Jr. et al., 1996). De modo especial, a PC será reforçada e exercitada à medida em que os resultados e o andamento do programa forem repassados e discutidos pela população, servindo inclusive para alimentar a auto-estima e a confiança da comunidade no serviço público (Briceño-León, 1994; Dias \& Dias, 1985). Um ponto de extremo valor na luta contra a SM é a discussão objetiva, em nível comunitário, das questões ligadas ao saneamento básico que permeiam o controle definitivo da endemia em grande número de situações (Amaral \& Porto, 1994). 
- Nas fases de consolidação do PCE, como acima apontado, o quadro epidemiológico transforma-se para pequenos focos de transmissão e redução da morbi-mortalidade (Kloetzel, 1967; Prata, 1997). Nesse, o controle da SM evolui naturalmente para uma etapa permanente de vigilância descentralizada, com epidemiologia própria de cada situação particular, em que a PC é imprescindível. Numa experiência recente em Pedro de Toledo, estado de São Paulo, Marçal Jr. et al. (1997) verificaram que após um programa convencional bem-estruturado e contínuo de diagnóstico e terapêutica da SM durante 12 anos houve significativas quedas nos índices de prevalência, de carga parasitária e morbidade da doença. Ultimamente, no entanto, as taxas de cobertura do programa estavam diminuindo, possivelmente em razão de uma situação de descaso da população com a SM, exatamente pela diminuição dos quadros graves e incorporação da doença ao cotidiano das pessoas, assoberbadas na sua vida por problemas muito mais graves e urgentes. Nessa fase, a PC institucionalizada e efetiva pode fazer uma grande diferença quanto às prioridades e encaminhamentos. De modo geral, e ainda conforme Marçal Jr. et al. (1997), a experiência tem demonstrado que a participação da comunidade pode chegar a ser razoável num programa de SM, levando-se em conta apenas as exigências atuais do programa. Essa constatação põe às claras uma deficiência histórica dos programas de saúde governamentais no tocante às relações com a comunidade em nosso meio: a visão limitada e imediatista dos responsáveis pelos programas, ao encarar a PC de maneira superficial e equivocada. Avaliando a PC em programas de saúde nas Américas na década passada, entre outros principais problemas, um grupo da Organização Pan-Americana de Saúde (OPS) apontava: "Más específicamente, existe una situación paradójica en la manera en que la mayoría de los sistemas de salud perciben la PC. A menudo dichos sistemas consideran que la PC es un complemento del sistema de salud, un medio para obtener la cooperación y los recursos adicionales para apoyar los programas del sistema de acuerdo con sus propias condiciones y bajo su control (...) La paradoja consiste en que la responsabilidad de la comunidad en las actividades y las condiciones de salud deriva de su participación y control en dichas actividades, aspectos que el sistema de salud generalmente no está preparado para fomentar o, en algunos casos, ni siquiera aceptar" (OPS, 1984:36). Pelo outro lado, e via de regra, essa participação comunitária se mostra muito aquém das potencialidades da comunidade e muito dissociada das tendências mais modernas de participação popular nos programas de doenças endêmicas, as quais exigem um grande envolvimento das populações-alvo na definição de políticas de saúde e no próprio desenvolvimento das ações de controle (Marçal Jr. et al., 1997).

\section{Doença de Chagas}

Largamente dispersa e exclusiva da América Latina, a doença de Chagas humana (DCH) é, dentre as chamadas grandes endemias, a que maior impacto de morbi-mortalidade produz na região (Schmunis, 1997). Em contraste com múltiplas complicações em seu tratamento específico, a DCH apresenta grande vulnerabilidade às ações de prevenção, mormente nas suas formas mais habituais de transmissão, pelo inseto vetor e por transfusão de sangue (Dias \& Coura, 1997). De um lado, a transmissão vetorial liga-se basicamente às relações de classe e de produção no meio rural, dependente das maneiras de o homem morar e das condições de sua vivenda (onde se aloja e coloniza o inseto vetor). Falta de higiene, pobreza, provisoriedade, subemprego, analfabetismo, anomia e uma extrema fragilidade política são elementos desse contexto. Do lado transfusional, a DCH se relaciona com a qualidade do sistema de saúde e com os fatores de migração interna que progressivamente carreiam doadores infectados para os centros urbanos, onde ocorrem as transfusões de sangue (Dias, 1993; Schmunis, 1997). No Brasil, a doença rural se urbanizou nos últimos quarenta anos, por causa da grande migração populacional. Em paralelo, mercê de um programa ministerial de controle dos vetores domiciliados (priorizado em 1982 e levado a cabo de maneira contínua desde então), os índices de transmissão declinaram drasticamente em mais de 95\% da área endêmica; na mesma linha, a doença transfusional experimentou enorme redução a partir da década passada, quando, principalmente sob a ameaça da AIDS, o nível de controle e de qualidade das transfusões de sangue sofreu sensível melhora no País (Dias \& Coura, 1997; Schmunis, 1997). Hoje a DCH encontra-se virtualmente controlada no Brasil, e o programa francamente em sua etapa de vigilância epidemiológica, restando como desafios a manutenção desta vigilância e o atendimento médico e previdenciário aos infectados remanescentes, cujo número se estima em torno de quatro milhões (Dias, 1997).

Exatamente na questão da vigilância epidemiológica e em sua prevenção, a DCH apresen- 
ta-se como importante modelo à $\mathrm{PC}$, o que será abordado em seguida. Na DCH tem-se uma situação similar à de algumas enfermidades imunopreveníveis, em que ações verticais e centralizadas, de maneira contínua e tecnicamente bem-conduzidas conseguem alcançar altos níveis de controle, mesmo na ausência de câmbios estruturais e econômico-sociais que fundamentam as raízes da endemia. Desde os trabalhos pioneiros de Emmanuel Dias, ficou claro que as chaves do controle da DCH estavam na prioridade política dada ao seu controle, à continuidade deste controle e à efetiva vigilância epidemiológica como etapa e estratégia de consolidação (Dias, 1958; Dias, 1987). Na transição político-demográfica de então (anos 60 e 70), nenhuma perspectiva havia para um programa minimamente suficiente de melhoria da habitação rural, assim como era ainda nebulosa e complicada a implantação de um programa nacional de bancos de sangue. Controlado o vetor no interior das casas, o impacto já seria enorme sobre a transmissão da DCH, tendo sido esta a base inicial do programa brasileiro. Optou-se então pela luta química sistematizada e racionalizada contra os triatomíneos domiciliados, o que foi feito por valorosas equipes da Sucam (a Superintendência de Controle de Endemias - Sucen - já lograra ótimos resultados em São Paulo), tendo este programa mantido suas bases técnicas operacionais praticamente até hoje, à custa de decisão política e de boa qualidade técnica. No bojo dessa determinação ocorreu decisiva participação da comunidade científica brasileira, não apenas denunciando com números a realidade epidemiológica da doença no País, mas estabelecendo as bases técnicas de um programa nacional e demonstrando sua viabilidade ao governo.

Em 1974, ainda em franco período de recessão, começaram os experimentos de vigilância epidemiológica, vislumbrando-se no horizonte os desafios da manutenção de uma atividade permanente quando a doença já estivesse sob controle e a densidade vetorial fosse muito baixa nos domicílios (Dias \& Garcia, 1978). A época era particularmente difícil, com um programa nacional contra a DCH ainda extremamente vertical e limitado, e um ambiente de ditadura, no qual qualquer reunião era encarada como suspeita ou subversiva, mormente se fosse percebido um processo de participação e organização comunitária. Não havia clima para reuniões, o Ministério da Saúde era distante e insulado, praticamente não havia sistema municipal de saúde e a desarticulação dos três níveis de governo era total, apesar de uma certa convivência pacífica entre eles. Lembre-se de que estávamos às vésperas de Alma-Ata, mas o País se encontrava institucionalmente ausente deste processo. Em tal contexto, foi gestado um programa pioneiro de PC em Bambuí, Minas Gerais, região até há pouco hiperendêmica. Trabalhando com professoras rurais do Município, um grupo técnico transdisciplinar elaborou um processo de discussão e planejamento conjunto sobre a DCH e suas possibilidades de controle, chegando-se a um projeto auto-sustentado para uma vigilância-piloto de cinco anos. Prefeitura Municipal e Ministério da Saúde acordaram sua participação no projeto, inclusive com presença nos treinamentos e alocação de recursos materiais e humanos, tudo isto referendado por um documento elaborado em conjunto com a própria comunidade. Por meio de encontros e planejamentos sucessivos, inclusive com visitas programadas às localidades rurais e estágio em laboratório, os professores das 36 escolas rurais levaram o problema e suas hipóteses: propunha-se que cada inseto suspeito capturado no Município fosse enviado às escolas rurais ou ao Centro de Pesquisas da Fiocruz, para exame e desencadeamento de uma visita técnica à casa notificante, com expurgo caso se tratasse do triatomíneo vetor. Coerente e pacientemente, o projeto foi até o fim dos cinco anos, com desdobramentos importantes no nível comunitário. Entre outros desdobramentos, o projeto desencadeou a formação de uma cooperativa local, houve reivindicação e providências quanto a vacinação e tratamento de enteroparasitoses na zona rural, houve atividades sobre hanseníase (outro sério problema no Município), houve estudo dirigido com os professores sobre direitos humanos e melhoramento de suas atividades pedagógicas etc. (Dias \& Dias, 1985; Dias \& Garcia, 1978). Analogamente, desdobramentos semelhantes também ocorreram num outro projeto de doença de Chagas levado a cabo em Cansanção, MG e descrito neste volume por Rosinha Borges Dias, o que reforça a validade deste tipo de abordagem. O esquema funcionou a contento, com resposta e participação da comunidade. Os professores resolveram e foram capazes de envolver mais de cem lideranças comunitárias nos encontros de planejamento e, ao fim do período aprazado, o projeto deixou sua formalidade e seguiu sozinho, mantendo-se automaticamente funcionante até os dias atuais, quando perfaz 23 anos de existência; os resultados finalísticos são excelentes: no nível de transmissão, sucessivos inquéritos sorológicos têm demonstrado a interrupção da transmissão; no nível demonstrativo, o programa mostrou-se viável e serviu como modelo da 
vigilância que a Sucam/FNS implantou em todo o País (Bryan et al., 1994; Dias, 1991). Das lições aprendidas deste programa, os próprios protagonistas (professores, técnicos e lideranças) depreenderam que o mesmo foi bem sucedido em termos de treinamento e execução por causa de (Dias \& Dias, 1985):

- o programa foi elaborado com base no concreto (coisas, interesses e necessidades reais das pessoas);

- baseado nesse concreto, os integrantes do grupo realizaram trabalhos e reflexões, um fazer e um pensar. Fazer: readmirar a própria realidade e aprofundar sua análise dessa realidade mediante visitas ao campo com roteiros, experiências de campo e laboratório, dramatização de situações familiares, levantamentos e entrevistas etc. Pensar: estudar essa realidade, geralmente em pequenos grupos, refletindo sobre o que foi encontrado e o que foi realizado;

- liberdade e flexibilidade no programa, conforme necessidade sentida e expressa pelo conjunto de participantes. Por exemplo, os temas dos encontros semestrais de avaliação foram selecionados pelo nível de interesse do grupo (votação, inclusive, entre 1974 e 1979);

- valorização constante do trabalho, com retorno e avaliações de rotina: reencontros formais e informais, visitas constantes às escolas, coerência na resposta à comunidade (expurgos pós-notificações), apresentação dos resultados às instituições e lideranças etc.;

- contato prolongado e continuado, pelos cinco anos aprazados com a população;

- integração da comunidade com serviços e instituições (saúde, educação, prefeitura, Sucam, Empresa de Assistência Técnica e Extensão Rural - Emater, Igrejas, Fiocruz);

- decisões democráticas e simplicidade no esquema.

A evolução do controle e da epidemiologia da doença de Chagas no Brasil aponta cada vez mais nos rumos da descentralização e da PC. De um lado, com a urbanização dos pacientes e a focalização e rareamento dos triatomíneos domiciliados, desaparece a racionalidade do grande programa vertical. Nesse quadro, também se acentua a progressiva e drástica redução dos vetores domiciliados, consistindo hoje em peridomiciliar a total maioria dos focos residuais (no peridomicílio não funcionam bem os inseticidas, daí requerendo-se a imprescindível participação dos moradores no que toca à organização, à limpeza periódica e ao manejo deste espaço. O peridomicílio funciona como ponta de lança à invasão do ambiente doméstico por triatomíneos silvestres da maioria das regiões chagásicas do Brasil, que o fazem à busca de alimento ou mesmo por terem sido desalojados de seus ecótopos naturais pelo próprio homem, em suas intervenções de plantio, desmatamento etc. (Dias \& Coura, 1997). Como outros exemplos de PC em doença de Chagas, lembrem-se dos casos da melhoria habitacional, da doença transfusional e da atenção ao infectado.

Quanto à melhoria habitacional, esta tratase de importante estratégia contra a transmissão vetorial da endemia. Praticamente os triatomíneos não logram domiciliar-se em vivendas higiênicas e de boa qualidade, cuja existência está naturalmente vinculada ao status social e econômico dos moradores e/ou a programas específicos de governo. Como a doença de Chagas incide exatamente sobre populações rurais, marginadas e excluídas, uma perspectiva programática e de amplo alcance no âmbito rural só pode ocorrer em termos de iniciativas governamentais, o que nunca aconteceu realmente no Brasil (Dias, 1987). De modo geral, não se podem entender programas habitacionais desvinculados de processo participativo. A habitação diz muito mais de perto ao povo que o inseticida, expressando vivamente a epidemiologia social da doença de Chagas, em termos da provisoriedade, da desagregação política e social, da instabilidade laboral e da falta de bens de produção da população exposta. Mexer na casa, por sua vez, é mexer diretamente com pessoas e com relações entre pessoas, intervenção profunda na estrutura microssocial, trazendo à tona problemas da economia grupal, da posse da terra e das relações de trabalho. Uma avaliação transdisciplinar do assunto entendeu ser obrigatória a PC em programas habitacionais, rechaçando-se formalmente campanhas demagógicas, transitórias e verticalistas nesse campo; no Brasil, verificou-se que muitas vezes a gente rural não melhora ou reconstrói a sua casa por várias razões profundamente existenciais, como falta de recursos ou posse do terreno, instabilidade laboral no lugar, desencanto e desestímulo em face da pobreza etc., nunca por mera 'ignorância', por 'preguiça' ou simplesmente por 'falta de vontade de melhorar' (Dias \& Dias, 1985). De maneira realística há que se admitir que, na realidade destas populações, praticamente todas as iniciativas hão de vir de fora, ser induzidas ou provocadas por gente e recurso externo, que nunca deverá ser impositivo, ignorar a população ou chegar com verdades prontas e interesses secundários. Isso é muito difícil, no contexto dos países e populações em foco, contemplando-se então, ao longo da América Latina, programas de habitação rural limitados, não 
participativos, descontínuos, verticalizados e geralmente pouco efetivos no nível do objetivo maior (melhoria social da população) e específicos (controle da doença de Chagas, por exemplo) (Dias, 1993). Por outro ângulo, quando possíveis e corretamente assumidos, programas habitacionais em áreas chagásicas podem propiciar inúmeras e riquíssimas perspectivas de ampla discussão da realidade local, de organização social, ajuda mútua, créditos rotativos; há o despertar de lideranças, cooperativismo, ampliação da comunicação etc., levando a comunidade a discutir mais profundamente seus problemas de base, inclusive os políticos e sócio-culturais, também aumentando sua autoestima (Briceño-León, 1994; Dias \& Dias, 1985).

No âmbito da doença de Chagas transfusional, hoje também em franca redução no País, a PC é oportuna inicialmente quanto à básica necessidade de que a população saiba e possa exigir transfusões de boa qualidade, corretamente indicadas e acessíveis a todos, cabendo ao Estado o aprovisionamento dessas condições. No estágio atual, a melhor estratégia de prevenção corresponde à triagem pré-transfusional de todos os doadores de sangue do país, por meio de reações sorológicas, o que está sendo conseguido em cerca de $80 \%$ a $85 \%$ dos casos. Esta estratégia já era possível há vinte ou trinta anos, mas foi somente com o advento da Aids, nos anos 80, que a triagem dos doadores foi sendo expandida, até tornar-se legalmente mandatória. Isso serve para ilustrar a questão do peso da mídia, da organização e da representatividade social (muito maior nos pacientes de Aids que nos de Chagas, sífilis ou hepatite) nas decisões políticas (Dias \& Dias, 1985; Dias, 1993).

a) Ainda sobre a doença de Chagas transfusional dois aspectos envolvem objetivamente a questão da PC: 1) mais genérica e institucionalmente, a disponibilidade de sangue (leia-se doadores conscientes e voluntários) e uma adequada política nacional de sangue e hemoderivados são problemas ainda em aberto, caso em que a PC se faz muito importante, seja no exercício da solidariedade consciente de toda a sociedade quanto à doação responsável de sangue, seja na concretização do SUS com vistas à boa hemoterapia a serviço de todos (com a ampla discussão social no nível de Conselhos e Conferências); e, 2) mais especificamente, emerge a questão do indivíduo chagásico, diagnosticado quando vai doar seu sangue e que vai necessitar e merecer atenção médica e eventualmente previdenciária (Dias, 1997). Lembre-se ainda de que a doença de Chagas transfusional é também uma questão de responsabilidade e competência de administradores, parlamentares e profissionais de saúde. A sociedade e a lei não podem aceitar sua ocorrência, dizia-se há mais de dez anos: "Para aqueles poucos que tratam do assunto irresponsável ou mercantilisticamente, a lei comum e a efetiva cobrança judicial deveriam necessariamente ser aplicadas....para não se arcar mais com este peso, originado apenas na ignorância de alguns e na má fé de uns poucos" (Dias \& Dias, 1985:134).

b) Atenção ao chagásico. Simplesmente lembrando-se de que ficará como o grande repto aos países e sanitaristas, ao controlar-se a transmissão, contemplando os 16 ou $18 \mathrm{mi}$ lhões de infectados já existentes na América Latina (Schmunis, 1997). Sendo em sua maioria os chagásicos pobres, rurais, dispersos e excluídos, os desafios mais essenciais corresponderão à efetivação e bom funcionamento do SUS, contemplados seus princípios de universalidade e eqüidade. Esse produto não se construirá sem ampla participação social, nas bases, na área técnica e nas áreas de governo e decisão. Ocorrendo a doença de Chagas, a comunidade organizada e a instância política têm que reivindicar, criar e fazer funcionar um sistema de diagnóstico precoce e de atenção adequada ao infectado, em sua maior parte manejável nos níveis primário e secundário de atendimento, mas também proporcionando os cuidados mais especializados àqueles $5 \%$ ou $10 \%$ de chagásicos que evoluem para as formas graves, estes últimos, inclusive, dependentes de previdência social (Dias, 1997). Certamente não serão os chagásicos - dispersos e sem representação - que lograrão isto, mas a parte mais consciente, engajada e responsável da comunidade, que deveria começar pelos segmentos científico e universitário.

\section{Outras endemias prevalentes:}

com alguns exemplos pontuais de problemas e possibilidades de Participação Comunitária

- Hanseníase (MH) e tuberculose (TBC). Doenças endêmicas ainda muito preocupantes no Brasil, a despeito de merecerem atenção especial (programa específico) por parte do governo. A MH apresenta ainda taxas de prevalência iguais ou acima de 10 casos/ 100.000 habitantes, sendo o grande desafio reduzi-la para $<1$ caso/100.000 habitantes no ano 2.000; a TBC mantinha níveis de incidência em torno dos 50 casos/100.000 habitantes em 1994, número este que poderá reduzir-se a $<15$ casos/100.00, como nos países desenvolvidos (Penna, 1994; Hijjar, 1994). Em termos gerais, não há maior 
obstáculo ao tratamento adequado dos doentes, havendo disponibilidade de recursos em termos de medicamentos e insumos necessários ao diagnóstico. Os programas próprios há anos se inseriram com prioridade na rede básica e o grande fantasma da resistência às drogas disponíveis não representa o principal problema. Ao contrário, no caso do $\mathrm{MH}$, a resolutividade terapêutica avançou muito com os esquemas de poliquimioterapia (pqt), mudando um conceito histórico de que o mal era de cura extremamente demorada e complexa. Na TBC, com tendência à redução da incidência e da mortalidade nos últimos lustros, a emersão dos quadros complicados com Aids e taxas inusitadamente altas em regiões especiais como o Rio de Janeiro têm que ser assuntos melhor avaliados. Ambas as doenças apresentam como problema principal, no Brasil, o binômio cobertura do diagnóstico e continuidade terapêutica. Isso significa hoje uma efetivação do SUS, que é a básica instância de atendimento e acompanhamento. Um alto nível de consciência social sobre estas doenças é requerido, como forma de superação de tabus e de viabilização do diagnóstico e do correto tratamento; a localização dos doentes e contatos não pode depender apenas de busca ativa por serviços gerais de saúde, com pouca mobilidade e pessoal geralmente assoberbado com outros agravos e tarefas. Como exemplo, é preocupante o fato de que nos anos 90 , entre $13 \%$ e $17 \%$ dos pacientes com TBC diagnosticada tenham abandonado seu tratamento (Hijjar, 1994). Dentre as estratégias mais efetivas a implantar, ou em vias de implantação, o eficiente funcionamento da rede básica de saúde, no nível municipal, corresponde à tarefa fundamental. Daí decorrem prioridades muito claras de PC, assinaladas por especialistas, que devem nortear as ações finalísticas quanto a estas duas históricas doenças. No nível mais geral, impõe-se "empenho nas negociações políticas (...) para alcançar a priorização do controle em todos os níveis do SUS e da organização político-administrativa do País", e "aumentar a participação de médicos gerais e outros profissionais, nas atividades de detecção e controle"; no campo da população, o desafio básico reside na ampliação dos conhecimentos sobre estas doenças, com vistas à detecção de casos novos e ao completo e adequado tratamento de todos os casos (Penna, 1994:43).

- Leishmanioses. A forma cutâneo-mucosa (LTA) é extremamente difundida no País, sendo vetor um mosquito (flebotomíneo) e principal reservatório, o homem. De enfermidade tipicamente rural, passou a urbanizar-se em várias partes do Brasil, como se tratasse de uma rura- lização de espaços urbanos periféricos. No princípio desta década, e francamente sub-notificados, registraram-se entre 10.500 e 22.000 casos novos de LTA no País, 50\% deles no Nordeste (Pereira \& Fonseca, 1994). O diagnóstico e o tratamento são relativamente simples, sendo exeqüíveis na maior parte do País; já a prevenção é complexa, principalmente quando residências e campos de trabalho (situações de vida e de trabalho) se alocam em encostas de morros e matas que são habitats prediletos do flebotomíneo. As estratégias de atenção partem dos casos diagnosticados e tratados, no nível de serviços básicos de saúde, requerendo ampla PC, que inclusive viabiliza ações de higiene peridomiciliar e facilita programas focais de desinsetização. Já o caso da leishmaniose visceral (LVA) é muito mais grave e também tendente à urbanização, com cerca de dois a três mil casos anuais registrados no País, 90\% deles no Nordeste (Monteiro et al., 1994). Na luta contra a LVA, além do esquema acima, tem-se usado com prioridade a estratégia de diagnóstico e pronta eliminação de cães infectados, através de pesquisa censitária nas áreas de transmissão ativa. Trata-se de outro ponto em que a PC e a educação sanitária são essenciais, envolvendo-se ampla informação e boa epidemiologia aplicada, espírito de visão do coletivo, eficiência das ações de controle etc. Não se pode esperar, por exemplo, que numa área endêmica de LVA, casos humanos permaneçam sem diagnóstico por falta de acesso ao SUS ou incompetência dos profissionais em realizar este diagnóstico e iniciar o tratamento, como tem sido muito freqüente; igualmente, numa localidade com transmissão ativa e programa instalado, uma demora dos laboratórios em processar o sangue colhido dos cães examinados por mais de vinte dias é no mínimo perda de tempo, cabendo às autoridades e à sociedade conhecer as causas dessa demora e instalar as providências. Lamentavelmente, entre as principais razões para a ineficiência desses laboratórios, têm-se destacado questões de natureza burocrático-administrativa, como técnicos funcionando em meio expediente, falta de cumprimento de pontualidade e horário, ausência de planejamento na disponibilidade de insumos, mau uso e falta de manutenção de equipamentos etc. São problemas pertinentes à comunidade, em que os implicados diretos muitas vezes não se dão conta do prejuízo social acarretado por sua incompetência ou falta de responsabilidade (de uma avaliação conjunta entre a FNS/MG, a Fundação Ezequiel Dias (SES/MG) e a Secretaria Municipal de Saúde de Belo Horizonte, outubro de 1996). 
Como um ponto crucial do programa integrado de LVA envolve adequada distribuição de recursos, hoje em sua maioria federais, um correto envolvimento político dos gestores é fundamental, podendo depender de negociações e ampla discussão com a sociedade, incluindo obrigatória presença de conselhos de saúde e comissões bipartites regionais nesse processo. Um exemplo disso ocorreu em Minas Gerais, recentemente, onde recursos de um programa ministerial (Programa de Controle de Doenças Endêmicas do Nordeste - PCDEN) foram repassados ao Estado para, entre outras destinações, aquisição de insumos na luta antiLVA, entre os quais veículos de captura de cães vadios para uso nos municípios. Possibilitou-se ampla discussão do assunto em nível técnico e da Bipartite Estadual, com vistas aos critérios técnicos e epidemiológicos adequados à distribuição dos carros, mas houve problemas e trabalho intenso para que critérios político-partidários muito fortes não mudassem totalmente o planejamento epidemiológico pré-acordado (Nota do autor, à época coordenador regional da FNS).

- Dengue e cólera. São endemias que recrudesceram no País nos últimos anos, em virtude de intensa movimentação humana e de insuficiência de vigilância epidemiológica quando da ameaça de sua reintrodução. Ambas apresentam alta velocidade de propagação e soem acometer grandes populações, se dadas as condições bioecológicas e sociais pertinentes. Em comum, ambas as doenças exigem para seu controle: um mínimo de saneamento básico, um mínimo de organização e eficácia do sistema de saúde e um alto nível de PC. No caso da cólera, sua ocorrência retrata de forma extremamente clara e fiel a pobreza e a falta de saneamento básico, enquanto, instalada a epidemia, os casos de morte corresponderão diretamente à fragilidade ou incompetência do sistema local de saúde. No auge da última epidemia brasileira, em 1992, chamou atenção a grande taxa de ataque ao Norte e Nordeste do País, exatamente nas áreas de pior saneamento básico, em contraste com uma mortalidade que sempre esteve baixa, por volta de 1\%. Quanto à comunidade, a ocorrência de cólera suscitou pavor e abalo na auto-estima, seja por causa de ancestrais imagens de morte e desolação, seja pelo reconhecimento de que a doença só se propagava por conta de uma miséria patente, que às vezes se tenta disfarçar. Importante notar que muito maior e permanente impacto negativo sempre fora observado nas áreas em questão, dado pelas clássicas doenças de veiculação hídrica, pela desnutrição e pela insuficiência de recursos assistenciais, redundante em altíssima e presente mortalidade infantil, que não emulava políticos e era paisagem e rotina para a população (um dos melhores produtos da cólera foi reduzir estes dados). A PC foi exercitada entre as pessoas e populações, estimulando-se a solidariedade humana e, de alguma forma, princípios de organização civil e de redes de informação. A evidência e o impacto da doença geraram desdobramentos e créditos políticos, naturalmente ensejando disputas, pressões e interesses, enquanto grandes recursos eram alocados, geralmente sem maior participação da população afetada. Registre-se, entre outros, um episódio marcante no nível federal, nunca repassado à população: vultosa verba emergencial foi liberada para obras e insumos nos municípios mais afetados, decidindo-se que metade do recurso sairia pelo Ministério da Saúde (MS) e a outra parte pelo Ministério do Bem-Estar Social, hoje extinto. Enorme esforço e inúmeras reuniões técnicas foram realizados, para cumprirem-se os exíguos prazos demandados pela emergência, o que foi logrado pelo MS a duras penas; no entanto, as verbas do outro lado não apareciam, complicando o produto final. O assunto clareou-se numa dificílima reunião técnica, quando alguém do MBES desabafou, explicando que ao MS competia prover saúde, mas que ao seu cabia dar sustentação política ao governo de então, tendo, portanto, que operar em outra lógica e em outra dimensão (Nota do autor, à época presidente da FNS).

A cólera permanece entre nós, mais suave e menos retumbante; dentre outras, uma lição quanto à PC destaca uma relação construtiva possível, quando as coisas e os esforços operam no nível do concreto e do cotidiano das pessoas. Pelo outro lado, a cólera também mostrou, lamentavelmente, que recursos aparecem e estimulam, mas que ações sustentadas nunca podem basear-se exclusivamente em aportes externos que a população não define nem controla: há dez anos, Ugalde (1987:29) já comentava a falência de programas de PC em saúde na América Latina, tratando exatamente destes pontos: "En los paises sub-desarrollados proyectos de PC son generalmente inducidos por agencias externas y gubiernos centralizados, hecho que genera un gran riesgo de transformar esos proyectos en modelos para introducir valores de la 'sociedad de consumo' en pequeñas comunidades, así como para controlar liderazgos, mano de obra o instituciones periféricas". Também é fácil entender por que projetos locais ou pilotos de PC podem manter a comunidade interessada enquanto perdura a assistência externa, e uma 'consciência política' da população não se desperta, em situações tradicionais 
latino-americanas, uma vez que - se efetiva e conseqüente - a PC conduz à organização comunitária e a atitudes naturalmente subversivas (Ugalde, 1987; Werner, 1980).

O dengue tem sido dentre as endemias, juntamente com a malária, o maior desafio a uma saúde pública eficaz e eficiente no Brasil, consumindo extrema energia e incontáveis recursos que nunca aparentam ser suficientes para resolver um problema que só faz aumentar. Sem vacina e sem terapêutica específica, o fantasma do dengue se concentra na explosão da transmissão e no espectro da forma hemorrágica, que demanda hospitalização em massa e pode ter alta letalidade. Os esforços mais viáveis dirigem-se para o controle do vetor (ou sua erradicação?), em que parte das ações depende diretamente do governo e uma outra parte - provavelmente hoje a maior no contexto das grandes endemias brasileiras - depende de efetiva e continuada participação da população. Parafraseando a Dra. Elmira Afradique, sanitarista mineira, pode-se dizer que o dengue tem uma das melhores propostas para o SUS, ameaçando toda a população, exigindo rede básica e cuidados secundários, requerendo medicina preventiva e não dispensando a participação de toda a comunidade. Somente como exemplo, o controle do Aedes (ou sua erradicação), passa muito além das caras e agressivas fumigações espaciais de fosforados (fumacê), tão a gosto de políticos e de empresas fornecedoras: é o controle larvário o ponto nevrálgico, a exigir verdadeira luta corpo-a-corpo no seio da população. E a epidemiologia tem mostrado, há anos, que os principais focos do mosquito entre nós residem no íntimo das habitações (focos em vasos de flores e entulhos de quintal), lado a lado com focos importantes em borracharias, lixões e ferros velhos (MS, 1996). Para o primeiro caso, somente a população organizada e motivada poderá acabar definitivamente com os criadouros, mercê de ação contínua e de longo prazo, introdução de alguns hábitos e mudança radical de alguns outros. Foi assim em locais como Honduras e $\mathrm{Cu}$ ba, recentemente. Para as últimas situações é mister uma cumplicidade e uma parceria entre comunidade, empresas e governo, seja na cobrança das medidas que se impõe, seja na formulação e implantação de posturas e códigos sanitários, a despeito de interesses setoriais de problemas orçamentários. Como demanda básica e subproduto altamente valioso, o problema do lixo tem que ser resolvido, em nível individual e coletivo. Em todos os casos, a PC se impõe e pode ser ampliada, como exercício de cidadania e de crescimento social, cabendo ao dengue, virose relativamente simples, ajudar a propiciar este desdobramento. Isso já fora acentuado por Bryan et al. (1994:70): "It is important to realize that community participation per se has inherent value because of its positive effect on the development of social relationships and community solidarity. Community involvement should not simply be considered yet another mechanism for controlling a particular health problem, or means for lowering operational costs in otherwise vertically structured programs, or a process for returning the burden of unresolved health issues to local populations. Rather, the dynamic process of community participation represents a necessary strategy for community survival...". As experiências vividas quanto à luta contra o dengue no Brasil têm sido ricas e pedagógicas no que toca à PC. Não obstante, essa participação carece de consistência e de continuidade, tendo sido pontual, irregular e quase sempre meramente casuística. Os esforços têm se dado basicamente na medida da doença instalada e de forte pressão governamental (inclusive com recursos e intensiva propaganda). Abaixados os níveis de transmissão e de infestação vetorial, quase que por encanto cessam os esforços comunitários e são afrouxados os trabalhos no nível local, o que praticamente inviabiliza hipóteses de erradicação e sempre deixa 'para o próximo verão', a ameaça da recrudescência. Quanto à consistência, um desperdício tem ocorrido nas campanhas de dengue, que seguem estimulando a PC de maneira muito restrita ao assunto específico do mosquito, portanto à margem de grandes temas da realidade social e da vida das populações expostas à doença. Também deixou muito a desejar a discussão do tema durante todo o processo da última Conferência Nacional de Saúde, a partir das etapas municipais. Um último ponto é oportuno neste exemplo do dengue, ligado à motivação da comunidade: em uma reunião técnica nacional no Ministério da Saúde (MS, 1996), ao se buscarem palavras-chave e de ordem à motivação da sociedade, curiosamente centrou-se de início no medo e no risco, para, ao final, acrescentar-se algo de auto-estima e confiança:

"O dengue mata, mas sua eliminação nós podemos conseguir".

\section{Algumas considerações à guisa de conclusão}

O tema é amplo e merece ser retomado, nesses anos de construção do SUS e de profundas mudanças nos rumos e perspectivas das grandes 
endemias brasileiras. A existência dessas doenças induz à formulação de um SUS prioritariamente aberto para as classes sociais excluídas e indica atitudes e posturas médicas e sociais que privilegiem as ações preventivas e a participação ativa e contínua de toda a sociedade. Também se deve lembrar que essas doenças endêmicas ocorrem em razão de desníveis sociais e distúrbios bioecológicos, cuja definitiva superação extrapola em muito o âmbito da medicina, incluindo obrigatoriamente nesta pauta a PC e muitos outros setores da população organizada e do governo, de forma sistêmica e racional. Na seção 2 deste artigo, alguns exemplos sobre perspectivas e problemas correlatos ao tema da $\mathrm{PC}$ e das endemias vieram à tona no cenário brasileiro, de modo geral demonstrando-se que alguns caminhos são possíveis e que a PC é um processo de lenta e permanente construção. Por outro lado, exemplificaram-se problemas e situações que comum e freqüentemente obstaculizam ou desvirtuam a PC, ressaltando-se o descompromisso de áreas técnicas e políticas com a população, a distância, a dependência da PC de recursos externos, a limitação da PC ao tema específico do 'projeto' ou da 'campanha' etc.

Nos anos 90, com a evolução da proposta do SUS, os rumos da descentralização se impuseram também nas questões da PC e do controle das endemias. Até mais que outras, estas doenças praticamente obrigam um enfoque através do sistema público, em face da população envolvida e do caráter eminentemente preventivo em seu combate. A princípio, hipóteses genéricas e tão a gosto de alguns setores, como terceirização, privatização ou provimento via seguros, têm pouca ou nenhuma viabilidade para resolver o problema das doenças endêmicas entre nós. Daí, como pressuposto que traga em seu bojo elevado nível de PC, um Estado forte e voltado para o social ainda se impõe, a despeito de fortes correntes em contrário. Essas correntes, naturalmente, não conhecem as endemias ou estão distantes delas, como o estão das populações por elas acometidas.

Sem dúvida, requer-se um caminho natural em termos de racionalidade técnica e de uma exigência intrínseca da implantação de um SUS que contemple as endemias, já que seria no mínimo incoerente a manutenção de programas verticais e em nível federal executando ações e programas em municípios e localidades afetados. Não obstante, uma série de problemas se apresentava quanto ao encaminhamento prático desta descentralização, entre os quais se destacam:
- A falta de conhecimento e prática na execução dos programas específicos, por parte de estados e municípios, ficando historicamente à União o trabalho a realizar e, por decorrência, a competência em fazê-lo (com exceção do Estado de São Paulo, que trabalhou com instituições próprias a partir de 1957 - Serviço de Profilaxia da Malária - SPM, Sucen). O controle das grandes endemias foi historicamente atribuição do nível federal, um modelo que vem da organização dos antigos Serviços Nacionais (malária, peste, febre amarela) e que chegou ao ápice quando se entendeu que a malária era erradicável e foi criada a Campanha de Erradicação da Malária (anos 50). Nesse sentido, a par de recursos e modelagem internacionais (o que já direcionava para um esquema federal), a própria doutrina da erradicação fazia pressupor uma operação altamente centralizada e uma organização paramilitar (Marques \& Cárdenas, 1994).

- A falta de entrosamento, de planejamento comum e de ações compartidas entre os níveis de governo. Nesse ponto, destaca-se o nível municipal, ao qual ficou cabendo a imensa maioria das ações a realizar, lembrando-se ainda das desarticulações 'horizontais', como a distância entre setores afins, como saúde, educação, justiça, trabalho, planejamento etc. Cabe refletir aqui, por exemplo, no enorme descompasso hoje visível entre as áreas sociais políticas e econômicas de governo em nosso País, com nítidos prejuízos e sofrimento para as populações menos favorecidas.

- A natural questão corporativa da categoria federal. De um lado, todo o problema de hierarquia e salários (geralmente melhores na União), dificultando a adesão ou aceitação dos servidores federais, que viam na descentralização um risco importante de perdas pessoais; de outro, uma preocupação em desmontarem-se estruturas e programas existentes sem saber ao certo como funcionar totalmente descentralizado.

- A incapacidade técnica e institucional em tratar-se a comunidade numa perspectiva histórica, pedagógica e politicamente adequada, gerando desencontros e frustrações, inclusive no que toca à implantação e funcionamento dos Conselhos de Saúde.

- A esperável resistência de fortes e vários setores da sociedade à implantação do SUS, em decorrência de altos interesses envolvidos.

- A ocorrência de um histórico modelo de medicina curativa (hospitalocêntrico) prevalente no País, deixando exíguo espaço às ações e temas de Saúde Pública, à PC, ao saneamento básico e à prevenção de doenças. 
No nível mais específico da PC com respeito ao controle de endemias, uma conclusão geral se coloca: ela se torna cada vez mais necessária em casos como a explosão do dengue e da definitiva implantação da vigilância epidemiológica (no caso de todas as grandes endemias), assim como é imprescindível para lograr de vez a cobertura e a continuidade requeridas em programas como os de $\mathrm{MH}$ e TBC. A PC no controle dessas doenças significa um processo em construção que requer impulso externo, competência em sua condução e liberdade para ampliar-se com autonomia e de modo autosustentado, democrático e responsável. Há ainda muito que aprender, em termos de postura e compreensão das equipes técnicas que se envolvem com a comunidade, muitas vezes de forma meramente burocrática e induzida de cima ou de fora, sem maior compromisso ou responsabilidade social. Nessa perspectiva, consideramos oportuno resumir os principais problemas inerentes à PC em saúde, na América Latina, levantados por expertos da OPS na década passada (OPS, 1984):

1) A contradição histórica entre a concepção médica da maioria dos sistemas governamentais de saúde (curativistas, paternalistas, centrados em doenças, verticais nas relações com a população), em face do enfoque preventivo, de companheirismo e mais amplo em relação a fatores sociais e ambientais, que pressupõe a PC.

2) A situação paradoxal, em que os sistemas governamentais de saúde percebem ou admitem a PC tão-somente como complemento e apêndice de sua própria lógica e de suas atividades, incapazes de aceitá-la como efetivamente controladora destas atividades.

3) A grande complexidade existente no câmbio de estruturas e mentalidade dos sistemas de programas de saúde, inclusive tomando-se em conta que a PC não pode ser usada como solução para todos os problemas.

4) A própria complexidade, o tempo necessário e a continuidade que se exige na formulação, na implantação e no exercício da PC, diante das necessidades e da realidade dos sistemas de saúde existentes.

5) As dificuldades de conciliação entre as prioridades de um programa, de uma política ou de uma equipe, com as prioridades e o momento histórico da população em pauta.

6) As maneira e a lógica na dotação e liberação de recursos, que muitas vezes determinam as prioridades ao invés de refleti-las.

7) As dificuldades de compatibilização entre os programas, no nível comunitário, e os grandes sistemas governamentais que os de- terminam e sustentam: que aprender dos projetos-piloto e como adaptar os elementos essenciais destes projetos aos grandes programas regionais ou nacionais?

Já do lado da comunidade (aqui falando-se de pobres e excluídos), problemas e debilidades quanto à PC têm sido apontados por outros estudos, como o de Hernandez (1996):

a) Provisionalidade: visão e expectativa comuns dos membros da comunidade, que esperam mudar-se tão logo alcancem melhores condições de vida, o que afeta o sentido de raízes comunitárias e diminui a internalização de compromissos com a comunidade e seu desenvolvimento.

b) A perda de sua memória histórica: como fundamento básico para qualquer mudança, a história comum tende a perder-se na pobreza das relações e na medida em que a identidade não se constrói, valoriza ou transmite a novas gerações.

c) Perda de relação entre o público e o privado: o público fica distante, não me diz respeito, não tem dono etc.

d) Paternalismo, altamente enraizado na cultura latino-americana, gerando dependência de gente de governo, resistência a mudanças, populismo e demagogias, mercado de influências, etc., além de inexorável visão fatalista de que 'minha vida está nas mãos de outros', seja o governo, ou mesmo Deus.

e) A subestimação das próprias capacidades, proveniente de uma falsa consciência de incapacidade e negatividade, reforçada por inúmeros fracassos e pela visão imediatista que a vida provoca, situação que dificulta o conceito e a prática de prevenção.

f) A desestrutura social, cada vez mais reforçada pela violência crescente e por reiteradas frustrações.

Para finalizar, e entendendo o tema como provocativo e indutor de reflexão, é cabível colocarem-se algumas questões de fundo, que emanam do grande desafio da PC e da Educação em sua perspectiva processual de formadores da cidadania, com vistas à formação dos legítimos sujeitos do desenvolvimento. Sua função insubstituível, como diz Demo (1986), é de ordem política, requerendo componentes importantes a serem assumidos por suas lideranças, tais como:

- "A noção de formação, não de adestramento, pois parte da potencialidade do educando, assumido como interessado primeiro do processo. - A noção de participação, de autopromoção e de autodefinição, ou seja, o conteúdo central da política social, entendida como realização da sociedade participativamente desejada. 
- A noção de sujeito social, não de objeto, de paciente, de cliente, de elemento.

- A noção de direitos e deveres, sobretudo os fundamentais, tais como os direitos humanos, os deveres do cidadão, o direito à satisfação de necessidades básicas, o direito à educação, etc.

- A noção de democracia, como forma de organização sócio-econômica e política mais capaz de garantir a participação como processo de conquista.

- A noção de liberdade, igualdade e comunidade, que leva à formação de ideologias comprometidas com processos de redução das desigualdades social e regional, com o desenvolvimento, a qualidade de vida e o bem estar culturalmente definidos, com a satisfação das necessidades básicas e a garantia dos direitos fundamentais. - A noção de acesso à informação e ao saber como instrumentos de crescimento da economia e da sociedade, bem como da participação sócio-econômica e política.

- A noção de acesso a habilidades capazes de potenciar a criatividade do trabalho, visto aqui como componente cultural, mais do que como simples elemento produtivo" (Demo, 1986:5253).

Tudo isso nos remete ao reconhecimento de que estamos ainda extremamente distanciados de um mínimo de participação da comunidade nos termos gerais de um processo

\section{Referências}

AMÂNCIO FILHO, A., 1994. Sobre o risco necessário de apostar no futuro. Cadernos de Saúde Pública 10:505-507.

AMARAL, R. S. \& PORTO, M. A. S., 1994. Evolução e situação atual do controle da esquistossomose no Brasil. Revista da Sociedade Brasileira de Medicina Tropical, 27 (Sup. 3):73-90.

BANCO MUNDIAL, 1993. Relatório sobre o Desenvolvimento Mundial 1993: Investindo em Saúde. Rio de Janeiro: Fundação Getúlio Vargas.

BARATA, R. B., 1993. O conhecimento epidemiológico na organização tecnológica do controle da malária, São Paulo, 1930-1990. Relatório Final ao Programa TDR de Pequeñas Becas de Investigación Socio-Económica en Enfermedades Tropicales. Caracas: Laboratório de Ciencias Sociales, Universidad Central de Venezuela.

BREILH, J. \& GRANDA, E., 1989. Epidemiologia y contrahegemonia. Social Science and Medicine, 28: 1121-1127.

BRICEÑO-LEÓN, R., 1994. Retos y problemas para alcanzar la participación comunitaria en el control de las enfermedades tropicales. Fermentum, 9: 165-176.

BRICEÑO-LEÓN, R. \& DIAS, J. C. P., 1993. Prólogo. In: Las Enfermedades Tropicales en la Sociedad Contemporanea (R. Briceño-León \& J. C. P. Dias, orgs.), social libertador, e particularmente no controle de doenças endêmicas. Num momento muito especial em que as ortodoxias estão se desmoronando, vê-se que as estruturas e a lógica tradicionais (inclusive as burocracias, a tecnologia, os sindicatos e os partidos políticos) são insuficientes para determinar o curso da História (Garcia, 1987). Na verdade, os projetos em curso têm sido paliativos, demorados, tecnocráticos e efêmeros, geralmente caracterizados por falta de conteúdo sócio-econômico e freqüentemente empurrados para situações assistencialistas e compensatórias, distantes das questões que mexem nas estruturas de produção e de poder (Demo, 1986). De fato, não se tem ainda um projeto definido de PC na construção do SUS e, menos ainda, luta contra as endemias, em termos efetivos de auto-sustentação e de uma parceria construída entre estado (provedor-estimulador) e a população (sujeito-efetora). Paradoxalmente, e quase que por ironia, no enfrentamento da malária, da doença de Chagas e do dengue tem-se aberto um espaço de exercício à participação e de avaliação crítica em nossa sociedade. É uma oportunidade adicional e concreta de rediscussão do Estado, que a população, organizações sindicais, igreja, universidade e legítimas lideranças deverão agarrar, na medida de seu ideal histórico e de sua responsabilidade social.

pp. 8-12, Caracas: Fondo Editorial Acta Científica de Venezuela/Consorcio de Ediciones Capriles.

BRYAN, R. T.; BALDERRAMA, F; TONN, R. J. \& DIAS, J. C. P., 1994. Community participation in vector control: lessons from Chagas' disease. American Journal of Tropical Medicine and Hygiene, 50 (Sup.):61-71.

DEMO, P., 1986. Participação é Conquista. Noções de Política Social Participativa. Fortaleza: Imprensa Universitária da Universidade Federal do Ceará.

DIAS, E., 1958. Profilaxia da doença de Chagas. $O$ Hospital, 51:285-298.

DIAS, J. C. P., 1987. Control of Chagas disease in Brazil. Parasitology Today, 3:336-341.

DIAS, J. C. P., 1991. Chagas disease control in Brazil: what strategy after the attack phase? Annales de la Societé Belge de Médecine Tropicale, 71 (Sup. 1):75-86.

DIAS, J. C. P., 1993. Situación actual de la enfermedad de Chagas en las Américas. In: Actualizaciones en la enfermedad de Chagas (R. Madoery, C. Madoery \& M. L. Cámera, orgs.), pp. 3-12, Buenos Aires: Congreso Nacional de Medicina.

DIAS, J. C. P., 1997. Controle da doença de Chagas. In: Clínica e Terapêutica da Doença de Chagas: Uma Abordagem Prática para o Clínico Geral (J. C. P. Dias \& J. R. Coura, orgs.), pp. 453-468, Rio de Ja- 
neiro: Editora Fiocruz.

DIAS, J. C. P. \& DIAS, R. B., 1985. Participação da comunidade no controle da doença de Chagas. Annales de la Societé Belge de Médicine Tropicale, 65 (Sup.1):127-135.

DIAS, J. C. P. \& COURA, J. R., 1997. Epidemiologia. In: Clínica e Terapêutica da Doença de Chagas: uma Abordagem Prática para o Clínico Geral (J. C. P. Dias \& J. R. Coura, orgs.), pp.33-66, Rio de Janeiro: Editora Fiocruz.

DIAS, R. B \& DIAS, J. C. P., 1986. Social and Cultural Attitudes that Affect Commitment Towards Vector Control. Geneva: WHO/VBC. Working Paper No. SG/WP/86.16.

DIAS, J. C. P. \& GARCIA A. L. R., 1978. Vigilancia epidemiológica con participación comunitaria. Un programa de enfermedad de Chagas. Boletín de la Oficina Sanitaria Panamericana, 84:533-544.

FREIRE, P., 1976. Ação Cultural para a Liberdade e Outros Escritos. Rio de Janeiro: Paz e Terra.

GARCIA, R. M., 1987. Tecnologia apropriada: amiga ou inimiga oculta? Cadernos da Fundap, 13:66-78.

HERNANDEZ, E., 1996. La comunidad como ámbito de participación. Un espacio para el desarrollo local. In: Participación. Ámbitos, Retos y Perspectivas (E. Hernandez, org.), pp. 21-44, Caracas: Ediciones Cesap.

HIJJAR, M. A., 1994. Tuberculose. Revista da Sociedade Brasileira de Medicina Tropical, 27 (Sup. III):23-36.

HOLLANDA, H. H., 1976. Saúde como Compreensão de Vida. Um manual de Educação para Saúde. Brasília: Ministério da Saúde/Convênio MEC/ Premen.

KLOETZEL, K., 1967. Suggestions for the prevention of severe clinical forms of schistosomiasis mansoni. Bulletin of the World Health Organization, 37:686-687.

MARÇAL Jr., O.; DIAS, L. C. S. \& GLASSER, C. M., 1997. Aspectos epidemiológicos e sócio-culturais do controle da esquistossomose mansônica no Município de Pedro de Toledo, São Paulo, Brasil. Relatório Final ao Programa TDR de Pequeñas Becas de Investigación Socio-Económica en Enfermedades Tropicales. Caracas: Laboratorio de Ciencias Sociales, Universidad Central de Venezuela.

MARQUES, A.C. \& CÁRDENAS, H. G., 1994. Combate à malária no Brasil: evolução, situação atual e perspectivas. Revista da Sociedade Brasileira de Medicina Tropical, 27 (Sup. 3):91-108.

MONTEIRO, P. S.; LACERDA, M. M. \& ARIAS, J., 1994. Controle da leishmaniose visceral no Brasil. Revista da Sociedade Brasileira de Medicina Tropical, 27 (Sup. 3):67-72.

MS (Ministério da Saúde), 1986. Relatório Final da VIII Conferência Nacional de Saúde. Brasília: Ministério da Saúde. Boletim Informativo no 4, 6 pp.

MS (Ministério da Saúde), 1996. Erradicação do Aedes aegypti. Brasília: Ministério da Saúde.

NAKAJIMA, H., 1989. Conference to Health Educators. In: Biomedical Science and the Third World: Under the Volcano (B. R. Bloom \& A. Cerami, eds.), New York: Annals of the New York Academy of Sciences, vol. 589.

OPS (Organización Panamericana de la Salud), 1984. Participación de la Comunidad en la Salud y el
Desarrollo en las Américas. Análisis de Estudios de Casos Seleccionados. Publicación Científica no 473. Washington: OPS.

OPS (Organización Panamericana de la Salud), 1997. Situación de los Programas de Malaria en las Américas: XLV Informe. Washington: OPS. Doc. $\mathrm{CD} 40 / \mathrm{INF} / 2$.

PENNA, G. O., 1994. Hanseníase: epidemiologia e controle. Revista da Sociedade Brasileira de Medicina Tropical, 27 (Sup. III):37-44.

PEREIRA, G. M. F. \& FONSECA, H. H. R.,1994. Leishmaniose tegumentar americana: epidemiologia e controle. Revista da Sociedade Brasileira de Medicina Tropical, 27: 45-50.

PEREIRA, G. M. \& TÁVORA, M. E. G., 1994. Epidemiologia. In: Esquistossomose mansoni (J. Malta, org.), pp.43-58, Recife: Ed. Universitária da UFPE.

PIMENTA, Jr. F.; DRUMOND S. C. \& DIAS J. C. P., 1996. Viabilidade e impacto do controle da esquistossomose em municípios de baixa prevalência de Minas Gerais. XXXII Congresso da Sociedade Brasileira de Medicina Tropical, Goiânia, GO. Resumo dos Trabalhos, p. 200.

PITT, D., 1983. Community Participation and Tropical Diseases Control. An Exercise of Partipatory Research. Geneva: WHO. Doc. TDR/SER-SWG 4.

PRATA, A. R., 1997. Esquistossomose mansoni. In: Tratado de Infectologia (R. Veronesi \& R. Foccacia, orgs.), pp. 1.354-1.372, São Paulo: Atheneu.

REMME, J. H. F.; DE RAADT, P. \& GODAL, T., 1993. The burden of tropical diseases. Medical Journal of Australia, 158:465-469.

RIVAS, P. H., 1985. Participación de la comunidad en la atención a la salud. Salud Pública de México, 27:402-409.

RODRIGUEZ, R.; SABROZA, P. C.; LEAL, M. C. \& BUSS, P. M., 1992. A ética do desenvolvimento e as relações com saúde e meio ambiente. In: Saúde, Ambiente e Desenvolvimento (M. C. Leal, P. C. Sabroza, R. H. Rodriguez \& P. M. Buss, orgs.), pp.31-45, São Paulo: Hucitec/Rio de Janeiro:Abrasco.

SCHMUNIS, G. A., 1997. Tripanossomíase americana: seu impacto nas Américas e perspectivas de eliminação. In: Clínica e Terapêutica da Doença de Chagas: Uma Abordagem Prática Para o Clínico Geral (J. C. P. Dias \& J. R. Coura, orgs.), pp.11-24, Rio de Janeiro: Fiocruz.

SILVA, A. R., 1988. Malária. Fotografia de uma Crise no Setor Saúde. São Luís: UFMa/MEC.

TAUIL, P. L., 1997. Epidemiologia da malária. In: Tratado de Infectologia (R. Veronesi \& R. Foccacia, orgs.), pp.1264-1268, São Paulo: Atheneu.

UGALDE, A., 1987. Las dimensiones ideológicas de la participación comunitaria en los programas de salud en Latinoamérica. Cuadernos Médico Sociales, 42:27-38.

WERNER, D., 1980. The village health care programme: community supportive or community oppressive? Contact, 57:1-16.

WHO (World Health Organization), 1993. The Implementation of the Global Malaria Strategy. Geneva: WHO. Technical Report Series N. 839.

XIMENES, R. A. A.; SOUTHGATE, B. \& SMITH, P. G., 1994. Controle da esquistossomose. In: Esquistossomose Mansoni (J. Malta, org.), pp.269-274, Recife: Ed. Universitária da UFPE. 